\title{
The effect of schema therapy on academic procrastination in elementary sixth grade students
}

\begin{abstract}
Purpose: This study examines the effect of schema therapy on academic procrastination.

Method: This study is Quasi-experimental Typical pretest- posttest with control group. The statistical population includes sixth grade female students in the city of Dezfoul. Thirty students were selected with step random sampling. They were then randomly assigned to control and experimental groups (each $\mathrm{n}=15)$. Experimental intervention was performed in 8 fifty minutes sessions on experimental group, and follow- up phase was followed one month after finishing the treatment. The Savari academic procrastination inventory was used to students.
\end{abstract}

Findings: The analysis of Univariate covariance (ANCOVA) showed that Schema therapy has significantly decreased the symptoms of academic procrastination in the experimental group. This result was the same significantly during the follow-up period.

Conclusion: The Schema therapy intervention in treating students' academic procrastination had been effective.

Keywords: schema therapy, academic procrastination, early maladaptive schemas, procrastination, students
Volume 9 Issue $6-2018$

\author{
Atefeh Aghaei,' Masoud Boroumandnasab,' \\ Mahnaz Mehrabizadeh Honarmand ${ }^{2}$ \\ 'Department of Psychology, Islamic Azad University, Iran \\ ${ }^{2}$ Department of Psychology, Shahid Chamran University, Iran
}

Correspondence: Atefeh Aghaei, Department of Psychology, Islamic Azad University, Ahvaz Branch, Ahvaz, Iran, Tel +98 917 742I552, Fax +98-07। I-7353502,

Email aghaei.atefah@ymail.com

Received: December 13, 2017 | Published: November 27, 2018

\section{Introduction}

An issue that has a negative effect on science progress among the students is procrastination in education. Procrastination is a universal problem that exists in all cultures. Such students try less and don't have enough perseverance in order to succeed and it is causes successive failures. Procrastination, in Latin language comprises of two parts, the first part is "pro" which means "beside" "in front" "protection, support" and the second part is "crastinus" which means tomorrow and literally if means until tomorrow. Its synonyms are cuntation, shilly- shally, Dilatoriness and delaying a work specially because of not paying enough attention, laziness and unnecessary delay. ${ }^{1} \mathrm{~A}$ problem in procrastination is intentional delay in academic field that is called academic procrastination. At studying estimated that 17 percent of male students and 14 percent of female student's procrastinate. ${ }^{2}$ rate of procrastination outbreak among Ahvaz payam-e-noor university students is $17.2 .^{3}$ One of the basic factors of cognitive system that is effective in continuation of procrastination is early inefficient schema. People who procrastination delete self- referral information from their information analysis system like depressed people and better remember their negative information, and this is the bias related to the person's inefficient schemas. ${ }^{4}$ Schemas comprise the basic part of the person's identity and are deeply related to the person's belief about himself and his surrounding environment and consist of everything the person knows, so changing them is so difficult. The patient resists against changing the schema and considers this resistance a kind of self- protection, so we cannot remove the schemas, but we can decrease activation and intensity of affection during recovery period and this requires having and iron will for fighting with schemas by the patient and exact discipline and a lot of practice. ${ }^{5}$ Changing Schemas is important because it is somehow changing the life style. ${ }^{4}$ The effect of inefficient schemas on our cognition results in the condition that the person wouldn't process the events properly, so improper analysis results in psychological disorders. In addition to psychological injuries that are resulted from early maladaptive schemas there are also schemas that can guide as towards procrastination and prevent changes. ${ }^{4}$ So early maladaptive schemas that motivate negative feelings in person are regarded a cognitive factor in forming and continuation of academic procrastination. in studying the relationship between coping styles and academic procrastination, examined a sample consisted of 310 university students of Mashhad university, showed that university students with issue- oriented coping style show less academic procrastination in comparison with emotion- oriented and avoidance - oriented coping styles. ${ }^{6}$ Examined the relationship between maladaptive schemas with procrastination and mental health in studying a 462-man sample of Shahid Beheshti medical sciences university students (232 person of medical group and 230 person of Non-medical group). The findings showed that there is a significant and positive relationship between early maladaptive schemas with procrastination and mental health and on the whole the result of this study confirms the mediation role of early maladaptive schemas in procrastination. ${ }^{4}$ there is a significant Relationship between academic procrastination and Academic progress. ${ }^{7}$ Investigated the effectiveness of combined communal- individual schema therapy on borderline personality disorder. The results showed that combined communal- individual schema therapy (ST) is so effective for borderline personality disorder and in addition, communal schema therapy speeds up the recovery in comparison with individual schema therapy. ${ }^{8}$ In another study, with the title of investigating the effectiveness of schema therapy in patients with borderline personality disorder, the findings show that although different results are achieved. But schema therapy is a good therapy and this therapy can be an economical strategy with positive economical outcomes in western and European societies. ${ }^{9}$ 
A study was performed with the title of "investigation of the effect of early maladaptive schemas in addicts and their wives", the results showed that the patients' and their Wives' early maladaptive schemas can be related and the patients got a higher score in companson with their wives in 13 if 18 schemas and that taking narcotic drugs is only related to a few early maladaptive schemas. ${ }^{10}$ The researches show the effect of schema therapy in Marital Satisfaction Enhancement, ${ }^{11}$ general anxiety, ${ }^{12}$ social anxiety, ${ }^{5}$ chronic depression. ${ }^{13}$ Now it is necessary to investigate the effectiveness of schema therapy in reducing academic procrastination as a new strategy in therapy process. Until now no investigation have been done about the effect of schema therapy in curing students' academic procrastination inside and outside the country, so helping these students is necessary regarding affirmation of the mediation role of maladaptive schemas in procrastination, the question is raised whether schema therapy is effective enough in curing students' academic procrastination? So the purpose of this study is effectiveness of schema therapy in reducing students' academic procrastination. So the following hypothesis is examined: schema therapy results in reducing academic procrastination in sixth- grade students.

\section{Methodology}

The present study is Quasi-experimental with pre-test and posttest and follow-up with control group. The statistical universe of this study includes all the Elementary Sixth Grade Female Students in The City of Dezful, (3020 students). The sample includes 30 sixth grade Female students who are selected according to step random sampling. For determining the sample, all the elementary schools for girls in Dezfoul are listed (76 schools) and 10 schools are selected randomly. Then academic procrastination inventory is presented for all the sixth grade students, and after gathering the inventories and classifying them according to the highest scores that show higher academic procrastination, 70 persons are selected and finally 30 persons are selected randomly and are divided randomly in control and experiment groups. Then the experiment group receives the intervention personally according to the schema therapy on the basis of the book of schema therapy ${ }^{14}$ that is 850 - minute sessions. During this period, the control group doesn't have any intervention. After finishing therapeutic sessions, the study's instrument is again presented as post- test and on month after finishing the therapy is presented as follow-up for experiment group and control group. Univariate covariance analysis (ANCOVA) is used for data analysis. Educational content that was presented every session is as follows: First Session: communication, empathy, familiarizing the students with the benefits of educational program of schema therapy, explaining schema model in simple language. Second Session: teaching core needs and the origins of schemata, identifying unconditional coping styles. Third Session: teaching about understanding five schema domains and 18 early maladaptive schemas, identifying the shemata. Fourth Session: using cognitive sterategies (Preparing and compiling schema's instructional cards while confronting schema's emotive condition). Fifth Session: using cognitive sterategies (communicating between healthy side and schema side), using behavioural patternbreaking (ommiting the perpetuative schema behaviour), Sixth Session: using experimental sterategies (rehearsal healthy behaviours through imagery and Role Playing), using interpersonal sterategies (reparenting while concentrating on imageries). Seventh Session: using experimental sterategies (writing letter and imagery dialogues with parents). Eighth Session: removing the barriers of shifting behavior, motivating the students to use educational programs' achievements through practicing in real life. The following instrument is used in the present study: 1-2-Academic procrastination inventory: this inventory is made by Savari ${ }^{15}$ through analyzing exploratory factor on 247 university students of Ahvaz payam-e-noor university (142 girls, 105 boys) that are selected with multi-stepped random sampling. And comprises of 12 items and 3 factors under the title of intentional procrastination (5 items), procrastination resulted from physical- mental fatigue (four items) and procrastination resulted from not having a program ( 3 items). In the academic procrastination inventory, two distinct samplings are used. The results of sampling adequacy index test $\mathrm{KMO}=0.760$ and Bartlett test of spherity $\mathrm{X}^{2}=$ $162.76(\mathrm{P}<0.0001)$ show that the data are suitable for factorial analysis. Analyzing exploratory factor shows that the special value of the first to the third factors is higher than one, and on the whole explains 61.11 variance of scales' items and 0.49 and higher factorial loadings are used in analyzing the factors of this inventory. Test reliability by cronbach's alpha for the whole test is 0.85 , for the first factor is 0.77 , for the second factor is 0.6 and for the third factor is 0.70 also test validity is determined by correlating with 16- question Tuckman procrastination test ${ }^{16}$ and its value is estimated 0.35 that shows the good validity of the test. The method of scoring the items is four- degree Likert scale: Always (5) most of the time (4), sometimes (3), rarely (2), never (1), that high score in this inventory shows high academic procrastination.

\section{Results}

Table 1 shows average, standard deviation, the scores of experiment group's and control group's academic procrastination in pre- test. Post- test and follow - up stage. As you see in Table 1, the average of the scores of academic procrastination in the experiment group in post- test and follow-up decreased in comparison with pretest, but there is not any decrease in the score in the control group. Table 2 shows the results of variable single covariance analysis (ANCOVA) for comparing the average pretest scores of groups' academic procrastination by controlling pretest. As you see in Table 2, there is a significant difference between experiment group and control group from the view of academic procrastinaton by controlling pretest $(\mathrm{F}=7.80, \mathrm{P}<0.001)$. So the hypothesis is confirmed. In other words, schema therapy results in reducing academic procrastination in elementary sixth grade students. The difference equals 0.23 and statistical power equals 0.76 . Table 3 shows the results of variable single covariance analysis (ANCOVA) for comparing average scores of groups' anxiety follow-up with pretest control Table 3 .

Table I Average and standard deviation of the groups in three steps of pretest, post- test and follow - up for the academic procrastination's score

\begin{tabular}{llll}
\hline Procrastination & & Statistical indexes & Stage \\
\cline { 1 - 2 } Standard deviation & Mean & & \\
\hline 9.29 & 23.66 & Experimental & Pre-test \\
8.17 & 24.33 & Control & post- test \\
10.03 & 16.26 & Experimental & follow- \\
2.43 & 25.66 & Control & up \\
8.88 & 15.33 & Experimental & \\
\hline
\end{tabular}


Table 2 The results of covariance analysis for comparing post-test's average scores of the groups' academic procrastination

\begin{tabular}{llllllll}
\hline $\begin{array}{l}\text { Statistical } \\
\text { power }\end{array}$ & $\begin{array}{l}\text { Eta } \\
\text { squared }\end{array}$ & $\begin{array}{l}\text { Significance level } \\
\text { of } \mathbf{P}\end{array}$ & F & $\begin{array}{l}\text { Mean } \\
\text { square }\end{array}$ & $\begin{array}{l}\text { Degrees of } \\
\text { freedom }\end{array}$ & $\begin{array}{l}\text { Total } \\
\text { changes }\end{array}$ & $\begin{array}{l}\text { Source of } \\
\text { changes }\end{array}$ \\
\hline 0.79 & 0.24 & 0.008 & 8.26 & 170.29 & 1 & 170.29 & Pre-test \\
0.76 & 0.23 & 0.01 & 7.8 & 160.73 & 1 & 160.73 & Group \\
& & & 20.6 & 26 & 535.6 & Error \\
\hline
\end{tabular}

Table 3 The results of covariance analysis for comparing Mean scores of groups' academic procrastination follow- up

\begin{tabular}{lllllll}
\hline Statistical power & $\begin{array}{l}\text { Eta } \\
\text { squared }\end{array}$ & $\begin{array}{l}\text { Significance level } \\
\text { of } \mathbf{P}\end{array}$ & F & $\begin{array}{l}\text { Mean } \\
\text { square }\end{array}$ & $\begin{array}{l}\text { Degrees of } \\
\text { freedom }\end{array}$ & $\begin{array}{l}\text { Total } \\
\text { changes }\end{array}$ \\
\hline 0.95 & 0.35 & 0.001 & 14.058 & 220.67 & 1 & $\begin{array}{l}\text { Source of } \\
\text { changes }\end{array}$ \\
0.5 & 0.14 & 0.05 & 4.23 & 66.48 & 1 & 220.67 \\
& & & & 15.69 & 26 & 66.48 \\
4
\end{tabular}

As you see in Table 3, there is a significant difference between experiment group and control group from the view of academic procrastination by controlling the pretest $(\mathrm{p}<0.00 \mathrm{I}, \mathrm{F}=4.23)$. The difference equals to 0.14 and statistical power equals to 0.50 .

\section{Conclusion}

The hypothesis that schema therapy results in reducing academic procrastination. The results achieved according to univariant covariance test shows that there is a significant difference between experiment group and control group. So schema therapy is effective in reducing academic Procrastination. The findings of this study is the same as the results achieved by previous studies of Yousefi, ${ }^{11}$ Zerehpoush et al., ${ }^{13}$ Khorshidzadeh et al., ${ }^{5}$ Hamidpour et al., ${ }^{12}$ Dickhaut \& Arntz, Sempértegui et al. ${ }^{9}$ The elements of schema therapy's approach consist of behavioral- cognitive approaches, gestalt, and attachment Constructionism and psychoanalysis in the form of a therapy model. This approach targets inefficient coping styles by identifying schemas and by using behavioral techniques helps the person to substitute a better coping style and reduces the symptoms of anxiety by embarking on the person's early emotional unsatisfied needs during the period of therapy. Experimental strategies allow him to tell his parents in a loud voice, what he needed in his childhood that his parents has denied to him. A student who procrastinates Learns by using cognitive techniques to reason against the schema and to question the validity of the schema in a reasonable level and understands that the schemas are thought to him by a process called "indoctrination". On the whole, regarding the effect of curing academic procrastination on students' performance and the result of the study that shows the effect of schema therapy approach on academic procrastination. It is suggested that method be used widely in schools and psychotherapic centers.

\section{Acknowledgments}

None.

\section{Conflicts of interest}

The author declares that there are no conflicts of interest.

\section{References}

1. Steel P. The nature of procrastination: a meta-analytic and theoretical review of quintessential self-regulatory failure. Psychological bulletin. 2007;133(1):65-94.

2. Shehni YM, Salamati S, Mehrabizadeh HM, et al. Prevalence Of
Procrastination And The Effects Of Cognitive-Behavior And Behavior Management Therapies On Reduction Of Procrastination In Male \& Female High School Students In Ahvaz. Journal of Education and Psychology. 2006;13(3):1-30.

3. Savari K. Study Investigates The Prevalence Of Academic Procrastination Among Boys \& Girls Students Of Ahwaz Payam-E-Noor University. Social Cognition. 2013;1(2):62-68.

4. Beigi AM, Bakhtiari M, Mohammadkhani S, et al. The Relation between Early Maladaptive Schema and Procrastination and Mental Health of Medical and Non-medical Students of Shahid Beheshti University of Medical Sciences. J Mazandaran Univ Med Sci. 2013;22(97):26-34.

5. Khorshidzadeh M, Borjali A, Sohrabi F, et al. The Effectiveness of Schema Therapy in the Treatment of Women with Social Anxiety Disorder. Research in clinical psychology and counseling (studies in education \& psychology. 2012;1(2):5-24.

6. Sepehrian F, Hosseinzadeh M. Structural modeling analysis of the relationship between coping styles and academic procrastination in students. Quarterly Journal of New Thoughts on Education. 2012;7(4):77-93.

7. Tamadoni M, Hatami M, Hashemi RH. General self efficacy, academic procrastination and academic achievement in university students. 20106(17):65-86.

8. Dickhaut V, Arntz A. Combined group and individual schema therapy for borderline personality disorder: a pilot study. J Behav Ther Exp Psychiatry. 2014;45(2):242-251

9. Sempértegui GA, Karreman A, Arntz A, et al. Schema therapy for borderline personality disorder: A comprehensive review of its empirical foundations, effectiveness and implementation possibilities. Clinical psychology review. 2013;33(3):426-447.

10. Shorey RC, Anderson S, Stuart GL. Early Maladaptive Schemas of Substance Abusers and Their Intimate Partners. J Psychoactive Drugs. 2013;45(3):266-275.

11. Yousefi R, Abedin A, Tirgeri A. The effectiveness of training intervention based on "schemas model" on marital satisfaction enhancement. Journal of Clinical Psycology. 2010;2(3):25-38.

12. Hamidpour H, Dolatshai B, Pour SA, et al. The efficacy of schema therapy in treating women's generalized anxiety disorder. IJPCP. 2011;16(4):420-431. 
13. Zerehpoush A, Neshatdoust HT, Asgari K, et al. The effect of schema therapy on chronic depression in students. Journal of research in behavioural sciences. 2012;10(4):285-291.

14. Young J, Klosko JS, Weishaar ME. Schema therapy: A practitioner's guide. Guilford Press; 2003.
15. Savari K. Study Investigates The Prevalence Of Academic Procrastination Among Boys \& Girls Students Of Ahwaz Payam-E-Noor University. Social Cognition. 2013;1(2):62-68.

16. Tuckman BW. The development and concurrent validity of the procrastination scale. Educational and psychological measurement. 1991;51(2)L473-L480. 